\title{
CONQUISTA E DESAFIOS NA CADEIA PRODUTIVA DA CAJUCULTURA NO RIO GRANDE DO NORTE: UMA ANÁLISE À LUZ DO DESENVOLVIMENTO REGIONAL SUSTENTÁVEL
}

\author{
Marcos Adller de Almeida Nascimento \\ Mestrando em Administração pela Universidade Federal do Rio Grande do Norte - UFRN \\ adller_almeida@yahoo.com.br \\ Washington José de Souza \\ Doutor em Educação pela Universidade Federal do Ceará - UFC \\ wsouza@ufrnet.br \\ Juarez Azevedo de Paiva \\ Mestre em Administração pela Universidade Federal do Rio Grande do Norte - UFRN \\ juarez.paiva@ig.com.br
}

\section{RESUMO}

O objeto de pesquisa tratado neste artigo é a gestão colegiada, adotando-se como espaço de investigação o ramo da Cajucultura e a atuação do Comitê Gestor da Cadeia no Rio Grande do Norte à luz do construto Desenvolvimento Regional Sustentável (DRS). É objetivo desta pesquisa revelar o modo como os membros deste Comitê Gestor interpretam as dimensões econômica, social e ambiental ante à composição da sustentabilidade nos empreendimentos. O referencial teórico elenca a Economia Solidária como estratégia para o Desenvolvimento Regional Sustentável. No que tange aos métodos, realizou-se um estudo de caso, tendo sido implementadas, junto aos atores envolvidos, entrevistas semiestruturadas. Esta pesquisa possibilitou concluir que as dimensões econômica, principalmente, e social, secundariamente, se sobrepõem, à dimensão ambiental. As ações em prol da cadeia são ainda restritas e de pouca efetividade, fato recorrente nas narrativas dos informantes e evidente quando analisados os preceitos do construto Desenvolvimento Sustentável.

Palavras-chave: Cadeia Produtiva da Cajucultura; Comitê Gestor; Desenvolvimento Regional Sustentável; Gestão Colegiada.

\section{ACHIEVEMENTS AND CHALLENGES IN THE PRODUCTION CHAIN CAJUCULTURA IN RIO GRANDE DO NORTE: AN ANALYSIS IN LIGHT OF THE REGIONAL SUSTAINABLE DEVELOPMENT}

\section{ABSTRACT}

The research target covered in this paper is the collegiate management, assuming as research the range the Cashew crop fields and the performance of the Chain Manager Committee in Rio Grande do Norte under the Sustainable Regional Development (SRD). This research aims to reveal the way in which the Manager Committee members interprets the economic, social, and environmental dimensions regarding the composition of sustainability on new developments. The theoretical reference includes the Solidarity Economy as a strategy to the Sustainable Regional Development. Regarding the methods, a case study was made, using semi-structured interviews along with individuals involved in these areas. The research led us to conclude that mainly the economic dimension, with social dimensions as a secondary, overlaps the environmental dimension. The actions supporting the chains are limited and with low effectiveness, a recurrent fact in the informants' narratives and were obvious when analyzing the precepts of the Sustainable Development.

Keywords: Productive chain of the cashew crop; Sustainable Regional Development; Manager Committee; collegiate management. 


\section{INTRODUÇÃO}

A partir de 2003, a Fundação Banco do Brasil (FBB) definiu como prioridade das suas ações a geração de trabalho e renda, incluindo, no Nordeste, a intervenção social na cadeia produtiva da cajucultura, mediante o incentivo à melhoria da qualidade dos pomares e a simultânea instalação de unidades de beneficiamento da castanha. Estabeleceu como diretriz o apoio, no campo, aos pequenos agricultores, àqueles da chamada agricultura familiar e assentados da reforma agrária.

Tais ações estão em sintonia com o Programa de Desenvolvimento Regional Sustentável do Banco do Brasil (DRS) e almejam a inclusão social de pequenos agricultores com base no ato cooperativo autêntico, no espectro da Economia Solidária. Assim, é buscado o equilíbrio entre três componentes fundamentais: viabilidade econômica, justiça social e consciência político-ambiental. Todavia, os desafios hoje colocados são significativos, visto que são necessários investimentos em recursos financeiros e em conhecimentos e técnicas para a melhora da qualidade da matéria-prima nas áreas rurais fomentadas. Há limitações na gestão da cadeia e dos empreendimentos em si, visando ao alcance da autogestão. Embora se tenha avançado na organização técnica e no planejamento dos empreendimentos, na construção e equipagem de unidades industriais e se tenha obtido algum resultado econômico, com avanços na comercialização, há impasses e desafios a superar no tocante ao comportamento organizacional, à autogestão e à observância aos preceitos do desenvolvimento sustentável.

O Projeto Minifábricas de Castanha de Caju tem o propósito de contribuir para a superação dos impasses e desafios impostos à cadeia. No Rio Grande do Norte, o Projeto conta com oito unidades de beneficiamento em funcionamento, abrangendo os municípios de Macaíba, Touros, Pureza, Açú, Apodi, Caraúbas. Severiano Melo e Portalegre com investimentos que superam R \$1,2 milhão (Fundação Banco do Brasil). No estado, conforme aponta o mapa abaixo, as unidades se concentram em três regiões: Litoral Leste, Litoral Norte Potiguar e Oeste.

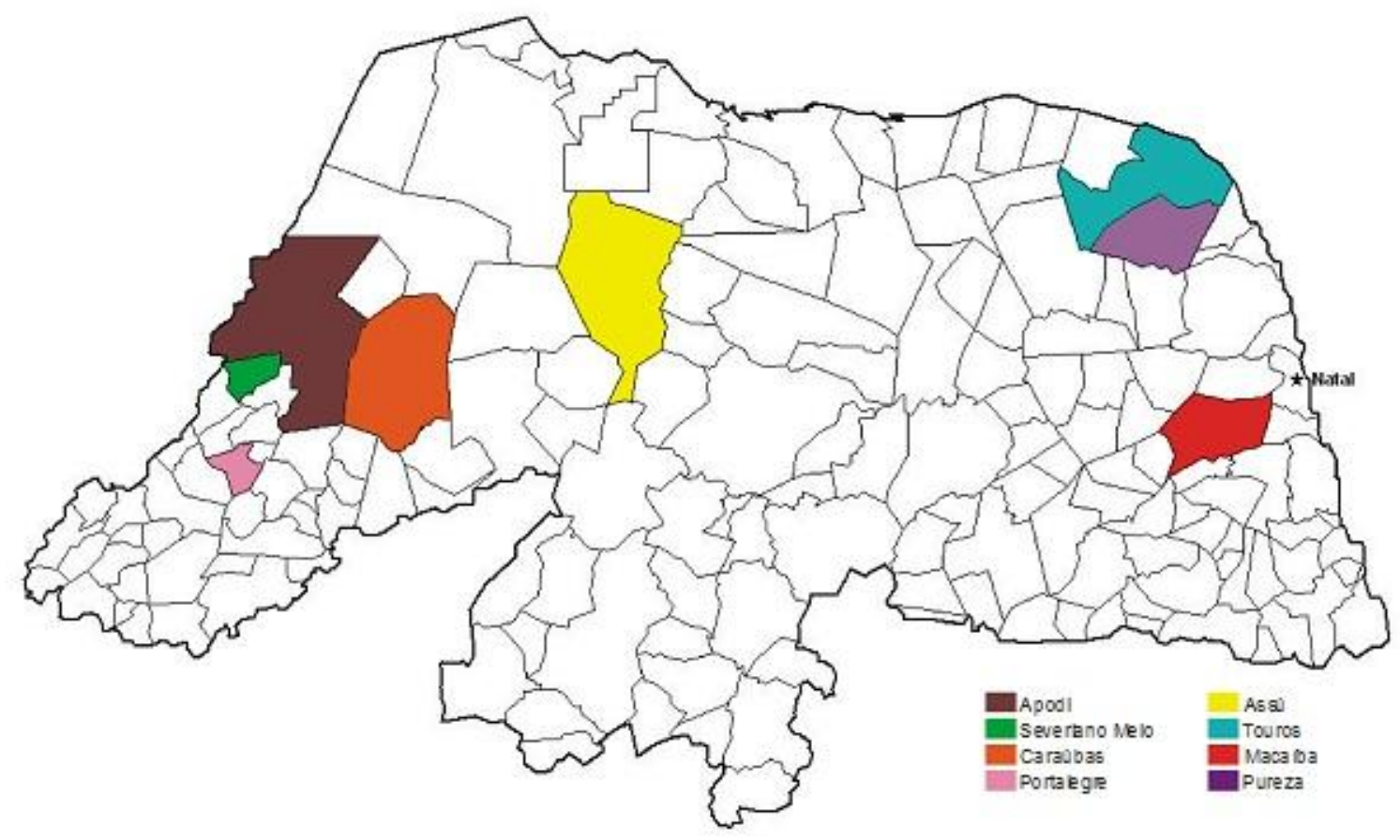

Figura 1: Municípios integrantes do Projeto de Beneficiamento da Castanha no Rio Grande do Norte

Fonte: Elaborada pelo autor 
A localização nessas duas regiões do estado, por si, indicam a existência de características particulares entre as unidades a partir da origem, pois, ao passo que as comunidades próximas à capital (Litoral Leste e Norte) possuem facilidades no escoamento do produto acabado, as localidades do Oeste têm dificuldades. Esta é apenas uma entre várias outras diferenças - a exemplo da existência de unidades fabris localizadas em áreas urbanas e próximas a elas, em assentamentos da reforma agrária e em comunidades rurais - a indicar o desafio de gerir a cadeia numa unidade gestora comum, o Comitê. É este o tema retratado neste texto: a gestão colegiada de uma cadeia produtiva.

Para tal exercício, o texto está assim composto. Economia Solidária como estratégia de Desenvolvimento Regional Sustentável, em que se discute o seu conceito e a importância que cada dimensão assume - econômica, social e ambiental - na estratégia de promoção ao Desenvolvimento Sustentável. Em seguida, é apresentado o procedimento metodológico para coleta de dados. Posteriormente, é feita a análise e a discussão dos resultados obtidos durante a coleta de dados e, por fim, as considerações finais.

\section{ECONOMIA SOLIDÁRIA: UMA ESTRATÉGIA DE DESENVOLVIMENTO REGIONAL SUSTENTÁVEL}

A Economia Solidária vem se solidificando como alternativa de desenvolvimento econômico aos modelos e padrões exploratórios da economia capitalista. Está claro que a Economia Solidária não atua em um campo fora do capitalismo e do mercado formal, mas, ao contrário, busca na realidade existente formas alternativas de produção e de desenvolvimento econômico baseadas em valores humanos, na busca da autonomia de grupos, em práticas sociais e ambientais sustentáveis. Sob este vasto conceito encontram-se referências às ações cooperadas e associativas, com vistas à autogestão, à atuação e à inserção no mercado por meio de redes e de relações de trabalho horizontais e equânimes.

Ao considerar o ser humano na integralidade, como sujeito e finalidade econômica, a Economia Solidária desenvolve as capacidades dos trabalhadores e trabalhadoras, valoriza o associativismo comunitário, o cooperativismo e o trabalho familiar na busca da inserção de atores excluídos do convívio social (Joyal, 2002). Trata-se de uma nova lógica de desenvolvimento e geração de trabalho e renda, mediante crescimento econômico e processos que garantem a proteção da natureza.

Parte-se do pressuposto que qualquer processo autogerido, além da produção da autossustentação, implica também dimensões não-materiais, tais como a liberdade, a autonomia e a autodeterminação. Essas dimensões são apontadas por Almeida, Villar e Nakano (in Gaiger, 2004, p.173) como "[...] processos não necessariamente espontâneos dos indivíduos, logo, passíveis de intervenções e fomento externo". O que se encontra na sociedade, em termos de relações de trabalho e geração de renda, é o processo histórico da dominação; são as práticas e valores de dominação que fundam o social em seu aspecto mais amplo (Singer, 2002, p.174).

A prática da Economia Solidária, em dimensão ampla, implica sujeitos organizados a partir da base, com vistas a romper a verticalidade absoluta das relações sociais e das relações de trabalho e poder inerentes à lógica capitalista. A participação e a autonomia são vistas pelos pesquisadores como conquistas dos atores sociais, que rompem com os modelos e padrões de relações trabalhistas para, a partir daí, se desenvolverem econômica e socialmente. De acordo com Oliveira (in Gaiger, 2004, p. 323) "O trabalho assalariado/remunerado, como forma de produção de capital, é visto como forma de mediação social" e, portanto, pode ser superado a partir da cooperação. Nas palavras de Singer (2002, p.9) "[...]a solidariedade na economia se dá se ela for organizada igualitariamente pelos que se associam para produzir, comercializar, consumir ou poupar”.

Vale considerar o valor da cooperação, entendido como forma de trabalhar em comum por

Revista de Gestão Social e Ambiental - RGSA, São Paulo, v. 6, n. 1, p. 38-52, jan./abril 2012. 
meio de movimentos coletivos em oposição à perspectiva individual. Nos empreendimentos solidários, a cooperação depende de cada um dos participantes (Jesus; Tiriba, 2003). As associações de trabalhadores constituem-se, assim, estratégia de mudança social a partir da produção cooperativa, característica esta que é própria do movimento dos trabalhadores. Os autores indicam a motivação para a cooperação entre trabalhadores sob duas perspectivas. A primeira, possibilita o entendimento de que a cooperação traz benefícios individuais; o outro enfoque recai sob a perseguição de valores referentes à solidariedade por meio de movimentos cooperativos e de ações voluntárias.

A perspectiva de redes de colaboração solidária considera aspectos econômicos e sociais como estratégia de relacionamento entre empreendimentos para realimentar e crescer de forma conjunta e autossustentável. Entre os objetivos da rede solidária, Mance (2003) identifica dois aspectos para tal conceito: de forma solidária as redes podem gerar novos postos de trabalho e distribuição de renda; o outro está voltado para a viabilidade econômica dos empreendimentos solidários, para o desenvolvimento.

Nesta perspectiva, parte-se para a discussão que permeia o conceito de desenvolvimento. Desde a década de 1940, este conceito vem evoluindo e deixando de ser atribuído à aspectos restritamente quantitativos para assumir cada vez mais um caráter qualitativo, de forma que, "[...] o que importa é deixar bem claro que desenvolvimento não se confunde com crescimento econômico, que constitui condição necessária, porém não suficiente" (Sachs 2004 apud Veiga, 2005, p. 9). De forma mais ampla, a concepção recente do tema desenvolvimento estaria associada à elaboração de projetos de reconstrução para países da periferia europeia no pós-guerra, mas que foram frustrados com a conferência de Yalta e o alinhamento dos países em bloco (Sachs, 2004).

Por sua vez, o debate em torno Desenvolvimento Regional Sustentável surge em contraposição ao modelo de desenvolvimento da segunda metade do século XX, que se deu com base na industrialização. De acordo com o relatório de Brundtland, de 1987, Desenvolvimento Sustentável pode ser entendido como um tipo de desenvolvimento que satisfaz necessidades presentes, sem comprometer a capacidade das gerações futuras, ou seja, um tipo de desenvolvimento capaz de manter o progresso e, no longo prazo, ser também alcançado pelos países em desenvolvimento.

No desenvolvimento regional sustentável, visualiza-se um processo que necessita apontar desafios presentes que cada ambiente (econômico, social, político e ambiental) possui para enfrentar sem comprometer as relações futuras. Para a Comissão Mundial sobre Meio Ambiente e Desenvolvimento (Cmmad, 1991) da Organização das Nações Unidas, é um conjunto de processos e atitudes que atende às necessidades presentes sem comprometer a possibilidade de que as gerações futuras satisfaçam as suas próprias necessidades. Para que tal processo tenha efetividade prática, se faz necessário implantar atos políticos de "[...]grande envergadura e alcance, capazes de superar as práticas políticas clientelistas, as negociatas, as alianças espúrias" (Almeida, 1994, p. 19).

É pertinente abordar a compreensão geral de desenvolvimento sustentável, fator que norteia a busca de pesquisadores e participantes dos processos em comunidades e grupos, pois se trata de termo que fundamenta a Economia Solidária, podendo ser visto e compreendido por meio de diversos construtos. Normalmente é vinculado (e, por vezes, confundido) ao crescimento eminentemente econômico, partindo da falsa premissa que a sociedade pode crescer indefinidamente e que a ciência e a tecnologia sempre terão mecanismos e soluções para as consequências deste crescimento. Morin (2005) critica a agressividade do desenvolvimento modelado apenas por valores econômicos, geradores de graves desequilíbrios socioambientais. $\mathrm{O}$ autor critica a monetarização e a mercadorização de todas as coisas, que destroem a vida comunitária e a ética da convivência social.

Milanez (in Cattani, 2003, p.76) entende que desenvolvimento sustentável significa "[...]uma

Revista de Gestão Social e Ambiental - RGSA, São Paulo, v. 6, n. 1, p. 38-52, jan./abril 2012. 
forma de ver o desenvolvimento de uma sociedade, ciente dos prejuízos causados ao meio ambiente pelo desenvolvimento econômico atual a fim de conciliar o processo de desenvolvimento social com a manutenção do equilíbrio ambiental do planeta." É importante analisar um elemento constante no cotidiano que permeia as relações humanas em diversos aspectos, a competição, e como a Economia Solidária propõe trabalhar tal aspecto. Existe um conflito, quanto aos aspectos de concorrência e competição de mercado, no que se refere ao excesso de competição versus a competição sadia. Singer (2002) se refere a este aspecto como diferencial entre as concepções de economia formal e a Economia Solidária. O autor aponta a heterogestão (oposto de autogestão), como um processo histórico e cultural de educação vertical. Este é um padrão social, de efeitos absolutamente negativos em termos de desenvolvimento sustentável e relações sociais equânimes, que pode ser processualmente rompido e trabalhado por meio de iniciativas junto às bases da sociedade (trabalhadores, produtores, famílias, grupos de diversas naturezas). Neste aspecto, projetos sociais têm um relevante papel de intervenção e transformação, com vistas à autonomia de grupos e comunidades. As práticas de Economia Solidária abrangem campos de atuação que não dizem somente respeito ao econômico. Retoma-se aqui a compreensão do constructo desenvolvimento sustentável, compreendido como um conjunto de resultados obtidos a partir da atenção a processos completos, desde a produção até o consumo, transpassando a forma de produção, a relação humana e de poder existentes nos grupos, os próprios grupos e formas de agrupamentos possíveis de serem geridos, os materiais utilizados para a produção e comercialização, distribuição e escoamento, o consumo e o consumidor dos produtos, os resíduos gerados e o seu destino.

Nesse sentido, exige que se pense de forma global, mas que se atue localmente. A procura de um novo enfoque do desenvolvimento regional leva, portanto, a uma perspectiva não eminentemente econômica, mas, também, a observações dos aspectos políticos, sociais e ambientais, que são, também, necessários ao crescimento e à manutenção de todos os agentes envolvidos (seres humanos, fauna, flora e a biodiversidade).

Para Sachs (1990), o desenvolvimento sustentável deveria estar baseado em três princípios básicos: a preocupação com o meio ambiente, entendida como condição para qualidade de vida; a eficiência econômica, capacidade de produzir mais e melhor com economia de recursos, capital e trabalho; e a justiça social, oportunidades semelhantes para todos.

Buarque (1995) considera que o processo de desenvolvimento deve se efetuar em três perspectivas ou dimensões: a) deve estar assentado na necessidade de elevar a qualidade de vida geral da população, com equidade social; b) os empreendimentos devem apresentar eficiência econômica; c) a conservação ambiental é um condicionante para a preservação do crescimento a longo prazo.

As dimensões "a" e "b" fazem parte de uma equação em que a combinação das forças políticas, econômicas e sociais determina o resultado. A dimensão econômica-social visa a otimização no uso dos recursos no processo produtivo, de forma a propiciar o crescimento econômico com inserção social, enquanto na dimensão de qualidade de vida predominam as forças políticas "[...]que tentam aperfeiçoar o processo que define ganhadores e perdedores no processo distributivo, num quadro de valores que refletem a "ética social contemporânea" (Flores e Silva, 1992).

Desta forma, a elevação da qualidade de vida e a equidade social constituem objetivos centrais do modelo de desenvolvimento; neste aspecto, a eficiência econômica e o crescimento econômico se constituem em pré-requisitos fundamentais para elevar a qualidade de vida, embora não sejam suficientes; a conservação ambiental é um condicionante decisivo da sustentabilidade do desenvolvimento e da manutenção no longo prazo, ou seja, para as gerações futuras. O desenvolvimento regional sustentável pressupõe, então, conquistas, continuidade e permanência da qualidade de vida e de oportunidades ao longo do tempo, incorporando uma perspectiva de longo

Revista de Gestão Social e Ambiental - RGSA, São Paulo, v. 6, n. 1, p. 38-52, jan./abril 2012. 
prazo e todas as dimensões relacionadas à preservação da vida humana e natural.

Mesmo havendo uma espécie de consenso quanto à necessidade de configuração de um novo padrão de desenvolvimento baseado na sustentabilidade há, ainda, um desafio: como tornar esse desenvolvimento viável em sistema econômico intensamente competitivo e degradador? Andrade (2001) alerta para a importância fundamental que tem a dimensão política na conquista e manutenção da sustentabilidade no desenvolvimento. Para que esse novo desenvolvimento aconteça se faz necessário democratizar o Estado, o que requer, entre outras demandas, a abertura do aparato estatal para o controle do cidadão. Torna-se necessário democratizar a própria sociedade, o que pressupõe o fortalecimento das organizações sociais, a democratização das informações e a capacitação para a tomada de decisões. Fala o autor, ainda, de outro tipo de capital importante para este tipo de desenvolvimento: o capital social. Acrescente-se, aí, a qualidade do capital humano, algo imprescindível a qualquer tentativa de mudança que se queira conquistar. É o capital humano qualificado que pode gerar capital social, promover a participação e buscar alternativas viáveis à promoção do desenvolvimento regional sustentável.

\section{ASPECTOS METODOLÓGICOS DA PESQUISA}

A corrente teórica que permeou esta pesquisa assumiu uma abordagem fenomenológica, pois, buscou estudar a gestão colegiada da cadeia produtiva da cajucultura: caracterizando o papel do programa de Desenvolvimento Regional Sustentável (DRS) do Banco do Brasil na política do Comitê Gestor da Cajucultura; analisando as conquistas e desafios na cadeia produtiva da cajucultura no RN, tomando como base interpretativa o modelo teórico de Sachs (2004); identificando conquistas e desafios, na atuação do Comitê Gestor, no tocante a implementação do programa de Desenvolvimento Regional Sustentável na cajucultura no estado; examinando os efeitos econômicos, sociais e ambientais na política do programa e, como cada ator interpreta a efetividade na política do programa, tomando como base a pauta e agenda do Comitê. Por fim, este estudo procurou comparar as dimensões adotadas pelo DRS do Banco do Brasil com a proposta teórica de Sachs (2004), visando à possível identificação de lacunas não contempladas pelo Programa.

A população pesquisada é definida como o conjunto de indivíduos que partilham de, pelo menos, uma característica em comum (Marconi, Lakatos, 1996; Levin, 1985). Desta forma, a população deste estudo foi formada pelas Entidades de Apoio e Fomento (EAF) e os Empreendimentos (Unidades de Beneficiamento) que constituem o grupo responsável pela formulação das ações em prol do desenvolvimento da cadeia produtiva da cajucultura. Desse conjunto foi extraído o grupo com presença mais efetiva nas reuniões do Comitê Gestor da Cajucultura no Rio Grande do Norte, totalizando 12 (7 gestores de empreendimentos e 5 representantes das entidades).

a) Os Empreendimentos Econômicos Solidários estão assim caracterizados:

- Associação do Projeto de Assentamento e Reforma Agrária José Coelho da Silva APARAJCS, localizada no município de Macaíba/RN. No momento, a Associação conta com 75 (setenta e cinco) associados, dos quais 26 (vinte e seis) ativos e 15 (quinze) trabalhando na unidade de beneficiamento da castanha. A Associação trabalha na perspectiva de promover $o$ Desenvolvimento Comunitário no Assentamento José Coelho da Silva, fortalecendo a organização social dos trabalhadores rurais. O grupo vem passando por entraves que dificultam a comercialização dos produtos, o principal deles, segundo o Presidente, diz respeito à entressafra, período compreendido entre o final da safra e início da outra. Neste período, os produtores passaram por dificuldades para atender às demandas do mercado, pelo fato de não existir uma política de estoque capaz de suprir esta necessidade. Para isso, considerando que a safra de castanhas de caju se concentra no período de setembro a dezembro, a minifábrica terá que se

Revista de Gestão Social e Ambiental - RGSA, São Paulo, v. 6, n. 1, p. 38-52, jan./abril 2012. 
preparar para adquirir e estocar matéria-prima nesse período, de modo a assegurar o funcionamento durante todo o ano. Porém, a restrição de capital de giro impede a formação de estoque;

- Associação Comunitária dos Produtores Rurais da Vila Assis Chateaubriand APROVILA, localizada no município de Touros/RN. A Associação conta, no seu quadro de sócios, com 36 (trinta e seis) associados, sendo 17 (dezessete) ativos e 14 (quatorze) trabalhando na unidade de beneficiamento. Tem como principal objetivo, a comercialização e gestão da produção das amêndoas de castanha de caju promovendo o aprendizado, pela via do trabalho, junto aos produtores rurais. $\mathrm{O}$ trabalho desenvolvido na Unidade de Beneficiamento, bem como as responsabilidades compartilhadas inerentes ao funcionamento da organização, têm sido constantemente negligenciadas por boa parte dos associados. O comprometimento de membros do grupo é acentuado e o ato associativo é precário e precisa ser trabalhado internamente por meio de palestras e formações em associativismo e cooperativismo;

- Associação dos Produtores Agrícolas de Bebida Velha - APABV, localizada no município de Pureza/RN. Conta em seu quadro de sócios com 39 (trinta e nove) associados sendo 27 (vinte e sete) ativos e 13 trabalhando na Unidade de Beneficiamento. O objetivo é contribuir para a geração de emprego e renda, agregando valor ao produto, gerando postos de trabalho e ampliando a comercialização da amêndoa, propiciando melhores condições de renda para as famílias, além de contribuir na melhoria da qualidade de vida dos produtores rurais. $\mathrm{O}$ grupo passa por dificuldades de relacionamentos interpessoais, com reduzido comprometimento dos trabalhadores da Unidade de Beneficiamento. Vem sendo trabalhado com o grupo, por meio da Incubadora Oasis/Unitrabalho, temas relacionados à responsabilidade, ao comprometimento e à valorização do grupo. Para acompanhar os resultados, foi firmado um contrato de convivência entre os membros do grupo, de modo que eles irão acompanhar as rotinas diárias na unidade de beneficiamento, identificando avanços e limitações;

- Associação do Projeto de Assentamento e Reforma Agrária Novo Pingos, localizada no município de Açu/RN. A Associação conta com 56 (cinquenta e seis associados), 40 (quarenta) ativos e 18 (dezoito) trabalhando na minifábrica e tem como objetivo ampliar a capacidade de beneficiamento de castanha, agregar valor ao produto e gerar postos de trabalho, aumentando a renda das famílias dos produtores e melhorando o bem-estar da comunidade. Identifica-se deficiência na comercialização e na gestão ambiental (reaproveitamento dos resíduos), diagnosticado em visita de formação pelos alunos da incubadora Oasis/Unitrabalho;

- Associação de Miniprodutores de Córrego e Sítios - AMPC, localizada no município de Apodi/RN, conta com 83 (oitenta e três) sócios, 78 (setenta e oito) ativos e 25 (vinte e cinco) trabalhando na unidade de beneficiamento. Com forte atuação no campo da cajucultura, a organização gera dezenas de empregos, de forma direta e indireta, no beneficiamento da castanha de caju, que, depois de beneficiada, é comercializada no mercado apodiense e para outros municípios e estados. O objetivo da Associação é agregar valor aos produtos produzidos. Ainda de maneira artesanal, são desenvolvidos vários trabalhos no Córrego, tais como a cajuína, doce de caju, amêndoas de castanha de caju e outros derivados do caju que hoje gera emprego e renda aos produtores.

- Associação dos Produtores de Castanha de Santo Antônio - ASSANTO, localizada no município de Severiano Melo/RN conta com 51 (cinquenta e um) sócios, sendo 45 (quarenta e cinco) ativos e 15 (quinze) trabalhando na unidade de beneficiamento da castanha. Tem como objetivo agregar valor ao produto, gerando postos de trabalho, aumentando a renda das famílias dos produtores e melhorando o bem-estar dos trabalhadores. A minifábrica está em operacionalização, porém algumas barreiras no tocante à comercialização e ao capital de giro são latentes, o que dificulta a sistematização das atividades relacionadas à gestão do empreendimento.

- Associação das Pequenas Comunidades Rurais de Portalegre - APCRP, localizada no município de Portalegre/RN conta com 290 (duzentos e noventa) sócios, sendo 84 (oitenta e quatro)

Revista de Gestão Social e Ambiental - RGSA, São Paulo, v. 6, n. 1, p. 38-52, jan./abril 2012. 
ativos. Tem o propósito de promover o desenvolvimento comunitário, proporcionar atividades econômicas, culturais e desportivas aos associados, bem como a melhoria do convívio da comunidade. A Associação tem participado de feiras nacionais de sustentabilidade e visitado, com frequência, as minifábricas de beneficiamento em outros municípios. Entretanto, no momento a unidade de beneficiamento da castanha encontra-se inoperante, em razão de vários fatores, desde a constituição de um grupo para trabalhar, que não existe, até as limitações quanto às revisões e manutenção dos equipamentos.

Em síntese, das 7 (sete) unidades, apenas 2 (duas), Açu e Apodi, operam com regularidade e já são constituídas como cooperativas. Porém, necessitam de melhorias nas áreas de comercialização e gestão ambiental. Quatro - Macaíba, Pureza, Touros e Severiano Melo - estão em estágio intermediário: requerem maior sistemática de acompanhamento desde a formação sociopolítica, até técnicas de gestão. Uma unidade, a instalada no município de Portalegre/RN, necessita de maior intervenção no tocante às formações, pois, se encontram em estágios embrionários no que se refere à articulação interna e coesão do grupo produtivo.

b) Outro grupo de informantes desta pesquisa é constituído pelas Entidades de Apoio, Assessoria e Fomento (EAF), também parceiras do Comitê Gestor da Cajucultura, assim caracterizadas:

- Fundação Banco do Brasil - FBB. A Fundação Banco do Brasil possui uma atuação consolidada e uma abordagem sistêmica na cadeia produtiva da cajucultura. Suas ações são voltadas para geração de trabalho e renda aproveitando as potencialidades regionais. Busca fixar o produtor no seu local de origem, aumentando a renda familiar. A Fundação assume papel na política de formação de estoque e aquisição de matéria-prima para as unidades de beneficiamento da castanha envolvidas no projeto visando à geração de trabalho e renda.

- Programa de Desenvolvimento Regional Sustentável do Banco do Brasil - DRS. Este programa busca impulsionar o Desenvolvimento Regional Sustentável na cadeia produtiva da cajucultura, apoiando as atividades produtivas envolvidas com as unidades de beneficiamento, no sentido de valorizar a cadeia, com ações integradas com os parceiros, de modo a contribuir para o desenvolvimento das comunidades envolvidas.

- Empresa de Pesquisa Agropecuária do Rio Grande do Norte - EMPARN. Tem o papel de incentivar o uso da tecnologia mínima nos pomares de cajueiros comuns de baixa produtividade, incentivando o uso de técnicas de substituição de copa e expansão da área de cajueiro anão precoce, usando mudas enxertadas e técnicas avançadas de produção. Dedica seus esforços para a viabilidade de soluções tecnológicas para a competitividade e a sustentabilidade da cadeia produtiva da cajucultura.

- Serviço Brasileiro de Apoio às Micro e Pequenas Empresas - Sebrae. O Sebrae, como parceiro do projeto, vem contribuindo para o fortalecimento da cadeia produtiva da cajucultura, implementando ações direcionadas ao aumento da produção, à melhoria da qualidade dos produtos e à promoção da qualificação e capacitação dos sócios trabalhadores das unidades de beneficiamento da castanha. Trabalha nas minifábricas de castanha de caju com o intuito de aumentar a produção e, consequentemente, a geração de novos empregos aos produtores rurais das comunidades contempladas pelas unidades de beneficiamento, além de capacitar as comunidades em áreas como gestão, empreendedorismo e práticas da cultura de cooperação, além de desenvolver e implantar um modelo de gestão adequado, moderno e dinâmico que garanta a funcionalidade das minifábricas.

- Companhia Nacional de Abastecimento - Conab. A Conab assume papel importante como parceira do Projeto, contribuindo na apresentação de ações de apoio à comercialização da castanha de caju. Destaca-se nestas ações a compra direta, modalidade que visa à aquisição de produtos da agricultura familiar em situação de queda de preços ou atendimento a demandas por alimentos em condições de insegurança alimentar. Destaca-se a castanha de caju, produto sazonal,

Revista de Gestão Social e Ambiental - RGSA, São Paulo, v. 6, n. 1, p. 38-52, jan./abril 2012. 
que requer uma política de estoque que possa atender às demandas nos períodos das entressafras. Vale ressaltar, também, o programa Compra Antecipada Especial da Agricultura Familiar também conhecido como formação de estoque da agricultura familiar. É uma modalidade que facilita a comercialização da produção da castanha.

\section{ANÁLISE E DISCUSSÃO DOS RESULTADOS}

A análise de conteúdo das entrevistas teve a intenção de alcançar os objetivos deste trabalho. Os dados foram coletados em entrevistas semiestruturadas e examinados pela via da Análise de Conteúdo. Os relatos dos entrevistados possibilitaram analisar e discutir os conteúdos dos temas referentes às conquistas e desafios na cadeia produtiva da cajucultura no RN, como também os resultados econômicos, sociais e ambientais da cadeia.

Para os empreendimentos, o esforço principal do Projeto, na fase inicial, foi a construção de 8 (oito) unidades de beneficiamento da castanha nos municípios de Macaíba, Touros, Pureza, Assu, Apodi, Caraúbas, Severiano Melo e Portalegre, além da construção de uma central de beneficiamento. Para (G4), “[...]a consolidação das unidades de beneficiamento da castanha[...]” foi uma das conquistas alcançadas pelo Comitê. As minifábricas proporcionaram oportunidades de emprego para membros da comunidade que não tinham perspectiva de inserção no mercado formal de trabalho. Corroborando com esta leitura, (G3) revela que a principal conquista foi "[...]conseguir as unidades de beneficiamento, que só veio gerar emprego e renda para as comunidades".

Outra possível conquista, na percepção de (G4), seria “[...]a consolidação da cooperativa central". Esta cooperativa seria responsável por comercializar todos os produtos da cadeia produtiva da cajucultura, o que, para (G6), ainda é um desafio posto ao Comitê. Foi citado por (G7), como conquista, "[...]o acesso ao crédito por parte do produtor rural, isto para mim é uma grande conquista". É compromisso do Banco do Brasil facilitar o acesso ao crédito para o produtor rural, oferecendo-lhe taxas de juros compatíveis com a realidade, de modo que possa custear seus produtos e garantir a sustentabilidade dos empreendimentos.

Destaca-se, na fala de (G6), o espaço e o reconhecimento que os grupos na cadeia produtiva da cajucultura e beneficiários do Projeto vêm obtendo conquistas junto à sociedade. "Hoje o produtor é reconhecido pela sociedade, é ouvido, é procurado pelo mercado". Pode-se atribuir tal reconhecimento à geração de trabalho e renda mencionada na questão 5 por $(\mathrm{P} 2)$ e $(\mathrm{P} 5)$, referente à dimensão social na unidade de análise inclusão social e qualidade de vida quando falam em "resgate da cidadania".

O planejamento integrado, elaborado de forma coletiva, é pautado na fala de (G5) como conquista alcançada pelo Comitê. "O planejamento é feito em conjunto com todos os membros do Comitê". Já (G6) identifica a integração dos parceiros no apoio aos empreendimentos: “[...]todas as instituições que participam do Comitê realmente abraçam a causa e estão aí, quando a gente necessita estão prontos a nos ouvir e atender nossas necessidades". Pode-se destacar, também, o pensamento de (P3) em relação às decisões que o Comitê vem tomando: "o Comitê Gestor tem sido feliz nas decisões, não há divergências, tudo é decidido em consenso". As ações discutidas de modo institucional e profissional nas reuniões do Comitê foram qualificadas por (P6) como conquistas: “[...]o amadurecimento nas relações institucionais, onde nós não percebemos nenhuma vaidade dos representantes, todos sempre procuram estar juntos com opiniões positivas, isso termina contribuindo positivamente para as comunidades assistidas". Este fato é ressaltado por (G2) como conhecimento adquirido nas reuniões do Comitê, onde tudo é levado à comunidade e isto vem sendo motivo de crescimento para eles. "Uma parceria muito interessante. Está fazendo com que nossa comunidade cresça e se desenvolva, tornando os cidadãos mais participativos".

A união em torno do cooperativismo e o compromisso dos parceiros em dar suporte aos empreendimentos e formular ações concretas em prol do desenvolvimento da cajucultura no Estado podem ser identificados nos discursos de (P5 e P4) também como avanços: “[...]a união do

Revista de Gestão Social e Ambiental - RGSA, São Paulo, v. 6, n. 1, p. 38-52, jan./abril 2012. 
cooperativismo entre os parceiros (empreendimentos) e a preocupação em formular ações concretas para a cajucultura de modo que promova algum resultado, isto para mim é, sem dúvida, a principal conquista do Comitê".

A diversidade de conhecimentos entre os parceiros envolvidos no Comitê é evidenciada por (P2) como uma "significante vitória". A Conab, no apoio à comercialização, o Sebrae na capacitação, a Fundação Banco do Brasil na assessoria e consultoria prestadas, a Emater e a Emparn na assistência técnica são aspectos que, segundo o entrevistado, tornam-se conquistas por parte do Comitê Gestor.

A conquista apontada por (P2) refere-se à ideia de sustentabilidade que o Comitê já conseguiu alçar: "[...]hoje, se uma das instituições precisar sair do Projeto, o Projeto não morre". Observa-se que o Comitê vai ganhando autonomia à medida que vai se solidificando o Projeto, do mesmo modo que as organizações parceiras continuam sendo importantes na execução, tornando, em contrapartida, os empreendimentos cada vez mais dependentes das entidades de apoio e fomento. Não são discussões, no âmbito do Comitê, a autonomia e autogestão dos Empreendimentos Econômicos Solidários.

Quando tratados os desafios postos ao Comitê, nas narrativas dos empreendimentos, 3 (três) aspectos devem ser retomados.

a) Promover a sustentabilidade e a autossuficiência dos empreendimentos são referendados por (G4) como desafios postos ao Comitê: "os grupos ainda são muito dependentes dos parceiros que compõem o Comitê”. Os grupos ainda não chegaram ao nível de estabilidade possível à emancipação. O posicionamento de (G1) revela-se da seguinte forma: "o desejo do Comitê é proporcionar estabilidade financeira e comercial às associações.

b) Manter a postura e dar continuidade àquilo que já foi alcançado é, na visão de (G6), um desafio, tendo em vista que, muitas vezes, as ações sofrem com a descontinuidade, o que acaba por dificultar ainda mais, conforme expõe (G5): "manter a postura e a posição que já alcançou e dar continuidade as ações propostas nas reuniões do Comitê".

c) Construção da central de comercialização, preponderou nas verbalizações o "sonho" de ver concretizado a central de comercialização, que, para os empreendimentos, irá contribuir para minimizar uma das principais dificuldades dos grupos no que diz respeito a comercialização. (G5) "O grande desafio, sem dúvida, é ver concretizado a central de comercialização, a cooperativa central", "concluir a central de cooperativas, isso, pra mim, é um desafio", "a central de cooperativas é um desafio ao Comitê Gestor" (G3).

Estes discursos são apoiados por uma das entidades parceiras. Para (P4), "o desafio seria constituir a central de comercialização vindo a melhorar e muito a vida dos empreendimentos no tocante a comercialização". Outra faceta, que emerge neste tema, divergente das demais posições assumidas, está na fala de (G2): "eu vejo dificuldades, por exemplo, no assentamento José Coelho. Nós estamos praticamente parados, porque os recursos chegam muito tarde, muitas vezes a safra já tem acabado". Este entendimento é dado igualmente por (P7) que, além dos recursos, pontua a gestão das minifábricas como um desafio ao Comitê: "A gestão dos recursos e das minifábricas eu acho que ainda está muito difícil, acho que é necessário treiná-los para a gestão". Aqui é importante lembrar Albuquerque; Zapatta (2007) quando registram que, apenas preparar os empreendimentos para a gestão não é suficiente: é necessária uma política pró-ativa e concertada de apoio à inovação e ao desenvolvimento das potencialidades das comunidades e região.

Outro ponto discutido refere-se à falta de compromisso por parte de algumas organizações que compõem o Comitê Gestor. Para Jofilsan (2007), a falta de compromisso dos parceiros envolvidos em alguma ação se manifesta quando não se sentem parte da ação e, assim, se negam a assumir qualquer tipo de responsabilidade. Segundo relato de uma das entidades de apoio, assessoria e fomento entrevistada, esta questiona a falta de compromisso por parte de algumas

Revista de Gestão Social e Ambiental - RGSA, São Paulo, v. 6, n. 1, p. 38-52, jan./abril 2012. 
entidades que compõe o Comitê. "Existe um parceiro que comparece a uma reunião e quatro não, cadê o compromisso, acho que o Comitê deveria cobrar mais a participação dessas entidades".

$\mathrm{Na}$ opinião das entidades representadas por (P1 e P2), o desafio ainda é a comercialização, "[...]conseguir mercados para comercialização", de modo que os produtores consigam escoar sua produção e garantir a sustentabilidade dos empreendimentos: "[...]eu digo, a comercialização é um desafio, capacitá-los e buscar mercados para comercialização também" (P2), desafio posto também por outra entidade que apóia os empreendimentos: "[...]o Grande desafio é a parte comercial dos produtos da cajucultura" (P6).

Desde então, a castanha do caju é um dos principais produtos da pauta de exportações do estado, com a maior parte da produção comercializada por meio de intermediários que operam como se fosse uma espécie de corretores das grandes indústrias de beneficiamento. Conclui-se que o desafio elencado pelos entrevistados seria a constituição da cooperativa central, que serviria como entreposto para a comercialização dos produtos.

Em relação aos conteúdos que deveriam estar postos na agenda do Comitê, e na opinião dos entrevistados - considerados desafios a serem enfrentados pelo Comitê - não estão, apresenta-se o teor da fala de (G6) que relaciona a preocupação com a saúde dos trabalhadores rurais envolvidos no projeto: "[...]ninguém colocou isso a sério, não é prioridade nas discussões do Comitê Gestor e essas pessoas correm muito risco no campo". Tal leitura é também formulada por (P2). Segundo o entrevistado todos os assuntos discutidos pelo Comitê relacionam-se à gestão dos empreendimentos: "[...] eu lhe digo que todos os itens que a gente tem conseguido pensar no sentido de melhorar os processos produtivos e de comercialização da cadeia produtiva da cajucultura estão sendo feitos e a melhoria do bem-estar do trabalhador rural"?

Outro ponto relevante nesta questão remonta à educação dos filhos dos produtores. Isso passa desapercebido na pauta de discussão do Comitê, segundo (P1): "[...]muitos dos filhos dos produtores estão fora da escola e esta lacuna, ao meu ver, deve ser preenchida de alguma forma". Sachs (2004) preocupa-se com a educação dos atores envolvidos nas comunidades numa perspectiva de inserção social e de desenvolvimento local.

Registra-se, ainda, nesta assertiva, a eficiência e efetividade da comercialização dos produtos que, não obstante, estão relacionados com a gestão dos empreendimentos, ponto este discutido na questão anterior nos discursos das entidades. Para (G6) trata-se de "[...]pautar mais na eficiência e efetividade da comercialização". Percepção semelhante tem (P10). Para ele, tudo é discutido, porém, não existe preocupação com o futuro dos empreendimentos: "[...]é discutido somente o presente e a continuidade destes empreendimentos são esquecidas". Neste viés, para Rutkowski (2007), gradativamente surgem políticas e ações paliativas de estímulos à sustentabilidade dos empreendimentos, tais como acesso ao crédito, financeirização, capital de giro e incubadoras de economia solidária que oferecem apoio na constituição e formalização dos empreendimentos. Essas ações criam condições institucionais de sustentabilidade, entretanto, são pensadas de maneira pontuais e não ajudam os associados a desenvolver dos instrumentos de gestão cotidiana, técnicas administrativas e econômicas de autogestão.

Essas lacunas comprometem a sustentabilidade dos empreendimentos levando a maioria deles a sobreviver em situações precárias, agravadas pela dificuldade de comercialização de produtos. Na visão de (P5) deveriam ser trabalhadas mais as oportunidades de financiamentos e capital de giro para os empreendimentos: "[...]capital de giro para dar suporte à sustentabilidade dos empreendimentos", aspecto que, segundo Rutkowski (2007), não contribui, por si, para a sustentabilidade.

Quanto aos efeitos econômicos, sociais e ambientais do programa de Desenvolvimento Regional Sustentável do Banco do Brasil na cajucultura, conforme relata (G4), há um distanciamento entre o real e o efetivo, ou seja, o que é defendido pelo programa como estratégia e o que é discutido nas reuniões do Comitê, classificando o discurso, até certo ponto, como

Revista de Gestão Social e Ambiental - RGSA, São Paulo, v. 6, n. 1, p. 38-52, jan./abril 2012. 
demagógico. "Acho até uma demagogia" (G4). Esta reflexão é sentida também no depoimento de (G1) ao relatar que "[...]sinceramente, no DRS eu não vejo ações concretas, em nenhum desses aspectos relacionados às questões econômicas, sociais e ambientais; só se for o econômico, que eles cobram muito resultado da gente".

Essas percepções apontam para descompassos entre os ideais e a prática voltada para a estratégia de Desenvolvimento Local Sustentável. A concepção ideal, apontada por Sepúlveda (2005), apresenta um modelo de Desenvolvimento Sustentável como uma função harmoniosa entre as dimensões econômica, social e ambiental. Em contraponto a esta fala, (G7) classifica como "boas" as propostas discutidas pelo Comitê ao observar os avanços nas áreas econômica e social, nas quais os gerentes de DRS despendem mais esforço. Para (G3), no Comitê, são discutidas ações que visam à melhoria, tanto econômica, quanto social e ambiental, mas são aspectos que precisam ser trabalhadas de maneira integrada: "[...]fala que nós não devemos nos preocupar somente com o econômico, mas também com o social e o ambiental" (G3).

Destaca-se na fala de outro associado a importância dos projetos de DRS que, segundo ele, têm contribuído para o desenvolvimento das comunidades beneficiadas a partir da implantação de minifábricas, mediante geração de trabalho e renda. "Eles sempre bate nestas questões econômicas, sociais e ambientais no sentido de proporcionar desenvolvimento para as comunidades" (G2). (G6) ressalta que o aspecto econômico sempre é discutido; por outro lado, temas sociais e ambientais precisam ser mais debatidas: "[...]o social e o ambiental é menos visível dentro do discurso dos gestores de DRS" (G6).

Associados afirmam que a estratégia de atuação do DRS do Banco do Brasil valoriza demasiadamente os aspectos econômico e social, em detrimento do ambiental. "O DRS está sempre em contato com a gente para saber os avanços econômicos e sociais; ambientais, nem tanto" (G5). Para este sujeito, existe uma cobrança por resultado, ou seja, o retorno daquilo que foi investido nos empreendimentos (minifábricas), financiado pelo Banco do Brasil. Em relação aos aspectos sociais, na opinião de (G5) o foco é a geração de trabalho e renda que as minifábricas estão proporcionando ao produtor rural: “[...]do social eles falam muito em geração de trabalho e renda para o produtor".

O DRS do Banco do Brasil é um programa que procura trabalhar o desenvolvimento de forma coesa. São abordadas as dimensões econômica, social e ambiental, porém, há uma nítida preocupação com o econômico, conforme este conteúdo de uma EAF: "[...]eu noto que a preocupação deles é mais o econômico" (P3).

A dinâmica que permeia a metodologia de DRS do Banco do Brasil é a da valorização de todas as dimensões, o que garantiria a sustentabilidade e autonomia dos empreendimentos. Para isso, existe uma preocupação por parte da instituição Banco do Brasil por meio do programa de Desenvolvimento Regional Sustentável, em deixar claro para os empreendimentos que estas dimensões são de fundamental importância para a sustentabilidade, sendo motivo de debates em todas as reuniões de Comitê Gestor: "[...] essa questão da sustentabilidade, o social, o econômico e o ambiental além do territorial já faz parte da agenda do Comitê" (P1). Resta questionar: para além do debate, como está a ação prática?

Nesta coleta de dados o informante (P2) ressalta que "[...]não só a econômica, mas, também, sociais e ambientais, a meu ver, vêm sendo assimiladas pelo público, não só da cadeia produtiva da cajucultura, mas, também, por outras cadeias [...] os resultados não são só econômicos, mas, também, sociais com a geração de trabalho e renda e, ambientais, através da conscientização do público envolvido na cadeia produtiva".

Por outro lado, (P4) é enfático ao relatar que "[...]dentro do Comitê Gestor, o valor econômico ainda é a vertente que domina as discussões". Complementando o entendimento da integração entre as três dimensões, Tiriba (2000) afirma que, nos espaços de discussões de ações voltadas ao Desenvolvimento Sustentável dos Empreendimentos, as conquistas são de cunho

Revista de Gestão Social e Ambiental - RGSA, São Paulo, v. 6, n. 1, p. 38-52, jan./abril 2012. 
econômico, mas, também, no âmbito social, educacional e cultural, de modo que possam promover um desenvolvimento ampliado para a vida e não somente para o empreendimento.

Há diferenças em relação ao discurso das entidades de apoio. Algumas revelam que estas dimensões são tratadas de forma homogênea, outras, de maneira desnivelada, sob ênfase na dimensão econômica, havendo distanciamento entre o ideal e o efetivo. (P5) corrobora com tal entendimento quando em seu relato expõe que as discussões que versam temas sociais e ambientais são de responsabilidade dos gestores de DRS do Banco do Brasil: “[...]as questões ambientais e sociais são assuntos da superintendência; eles que discutem esses pontos, porém, não devemos deixar de lado; estas questões são de fundamental importância para a sustentabilidade dos empreendimentos" (P5).

\section{CONSIDERAÇÕES FINAIS}

Este artigo buscou analisar, à luz do Desenvolvimento Regional Sustentável, as conquistas e os desafios na cadeia produtiva da cajucultura no Rio Grande do Norte, tomando como base interpretativa o modelo teórico de Sachs (2004), tendo sido elaborado, portanto, a partir da perspectiva de desenvolvimento defendida pelo autor. A consideração de Sachs, de que determinado modelo de desenvolvimento só poderá ser considerado sustentável se houver progresso simultâneo das dimensões econômica, social, ambiental, política e territorial, norteou a elaboração deste estudo. A representação do modelo proposto pelo autor mostra a inter-relação e a conexão entre essas dimensões de desenvolvimento sustentável.

Para caracterizar aspectos relacionados às dimensões de desenvolvimento, elencados pelo Comitê, foram construídas unidades de análise a partir de três dimensões: a) Econômica: Gestão Econômico-Financeira, Infraestrutura, Custos e Receitas; b) Social: Organização Social, Inclusão Social e Qualidade de Vida, Geração de Trabalho e Renda e Capacitação dos Sócios; c) Ambiental: Ecoeficiência, Gestão Ambiental e Regulamentações Legais. Certamente existirão outras dimensões, destas derivadas, caracterizando uma multiplicidade e complexidade de conhecimentos acadêmico-científicos associados ao fenômeno pesquisado. Todavia, para efeitos de viabilidade empírica, foram adotadas essas três que se encontram presentes na proposta apoiada pelo Banco do Brasil dentro do seu programa de Desenvolvimento Regional Sustentável (DRS).

$\mathrm{Na}$ dimensão econômica, a categoria que obteve consideração inferior entre os entrevistados nesta pesquisa foi "custos". O menor nível de consideração é expresso pela dificuldade do acesso ao crédito pelos empreendimentos, em razão das barreiras impostas pelas instituições de crédito, vindo a comprometer os resultados operacionais das unidades, além do preço elevado da matériaprima. Entre as que são consideradas em maior grau estão: gestão econômica e financeira e infraestrutura. Destaque-se, aqui, o apoio recebido pelos empreendimentos por meio das entidades de assessoria e fomento, que, segundo os entrevistados, garante a viabilidade econômica e as receitas, melhorando a distribuição de renda ao longo da cadeia de valor.

Em relação à dimensão social, a categoria que obteve consideração inferior entre os entrevistados foi capacitação dos sócios, mesmo que com reduzido avanço. Entretanto, constatou-se nesta pesquisa que os sócios não estão capacitados para a autogestão dos empreendimentos, sendo esta uma fragilidade na visão das entidades de apoio e fomento que compõem o Comitê. Observações advindas do acompanhamento do pesquisador durante a fase da coleta dos dados apontam que a rotatividade de pessoal é elevada e isto, em parte, explica a dificuldade no alcance de regularidade nos processos de gestão.

Entre as que são consideradas em maior grau estão a organização social envolvendo a integração e a participação da comunidade na gestão da cadeia. Para Barros (2007), a participação entre os atores de uma determinada cadeia produtiva visa à integração dos processos e contribui para a geração de trabalho e renda, estimulando a ética da confiança e a cooperação entre os envolvidos. Registrem-se considerações feitas pelos entrevistados às categorias inclusão social e

Revista de Gestão Social e Ambiental - RGSA, São Paulo, v. 6, n. 1, p. 38-52, jan./abril 2012. 
qualidade de vida e à geração de trabalho e renda. Para os informantes, a cajucultura vem contribuindo para a geração de trabalho e renda nas comunidades beneficiadas e, com isso, melhora a qualidade de vida do produtor rural e sua família.

Em relação à dimensão ambiental, as categorias que obtiveram considerações inferiores entre os informantes desta pesquisa são ecoeficiência, gestão ambiental e regulamentações legais. É frágil o discurso e as ações direcionadas à prevenção dos problemas que a cajucultura pode provocar ao meio ambiente e ao homem. Observou-se que a preocupação do Comitê restringe em orientar o produtor a não queimar a casca sob o risco de estarem sendo multados pelos órgãos fiscalizadores. Segundo Pinzón (2007), a gestão ambiental é bastante ampla e vai desde a formulação de políticas públicas até a conscientização e envolvimento dos diversos setores da sociedade. Não é este o caso analisado. Na visão dos empreendimentos, a estratégia de atuação do DRS do Banco do Brasil valoriza mais os aspectos econômicos e sociais em detrimento do ambiental, ainda que se esteja tratando de uma atividade periculosa, poluente e insalubre.

Quanto aos conteúdos que deveriam estar postos na agenda do Comitê, e na opinião dos entrevistados não estão, destacam-se dois pontos importantes não contemplados. $\mathrm{O}$ primeiro diz respeito à saúde do trabalhador, conforme registrado anteriormente. A cajucultura é caracterizada como uma atividade poluente, periculosa e insalubre. Entretanto, não há direcionamentos nas discussões do Comitê relacionados à saúde do produtor rural. Neste caso específico, a atividade leva o ser humano ao contato direto com um produto perigoso à saúde. Outro ponto está relacionado à educação dos filhos dos produtores rurais, tendo sido este um tema trazido por um dos gestores da política de DRS do Banco do Brasil. Entretanto, vale registrar que o Banco do Brasil tem um programa denominado Educar Banco do Brasil destinado aos produtores e seus filhos, porém, este programa não foi citado durante a entrevista pelo informante. Neste sentido, Sachs (2004) destaca a importância da educação para os atores envolvidos nas comunidades rurais como forma de inserção social e desenvolvimento local.

Por fim, quanto à estratégia de operacionalização do DRS do Banco do Brasil, conclui-se que as decisões e ações estão mais fortemente focadas na dimensão econômica e têm reduzida efetividade, de acordo com experiências narradas pelos sujeitos. Tal resultado, quando interpretado à luz dos preceitos do desenvolvimento sustentável, permite afirmar a restrita observância, por parte do Comitê, às dimensões social e ambiental.

\section{REFERÊNCIAS}

Albuquerque F., Zapata, T. (2007) Importância da estratégia de desenvolvimento local/territorial no Brasil. In: Zapata, T. (org.). Desenvolvimento local e participação social. Recife: Editora. Elógica, 59-78.

Almeida, J. M. G. (1994) Desenvolvimento ecologicamente auto-sustentável: conceitos, princípios e implicações. Revista humanidades, n. 38. Recuperado em 6 abril 2009, de://www2.camara.gov.br/publicacoes/estnottec/tema11/pdf/002463.pdf>

Andrade, I.A.L. (2001) O desenvolvimento sustentável entre o discurso e a prática. In: O município no século XXI. Natal: PROEX/UFRN e Konrad Adenauer Stiftung.

BUARQUE, S.C.(1995) Metodologia de planejamento do desenvolvimento sustentável. Recife.

Cattani, A.D. (org) (2003). A outra economia. Porto Alegre: Veraz Editores.

Revista de Gestão Social e Ambiental - RGSA, São Paulo, v. 6, n. 1, p. 38-52, jan./abril 2012. 
Flores, M. X., Silva, J. S.(1992) Projeto EMBRAPA II: do projeto de pesquisa ao desenvolvimento sócio-econômico no contexto do mercado. Brasília: SEA/EMBRAPA.

Gaiger, L.I. (Org.) (2004) Sentidos e experiências da Economia Solidária no Brasil. Porto Alegre: Editora da UFRGS.

Jofilsan, P. (2007) Gestão de compromisso. In: Zapata, T. (org.). Desenvolvimento local e participação social. Recife: Editora. Elógica, 45-57.

Joyal, A. (2002) Le developpement local: Commet Stimuler I'économie des regions en difficulté diagnostic, les press de I'unversité laval.

Mance, E.J. (2003) Cadeias produtivas solidárias. In. Cattani, A.D. A outra economia (org). Porto Alegre: Veraz editores.

Marconi, M. De A., Lakatos, E. M. (1996)Técnicas de pesquisa: planejamento e execução de pesquisas, amostragens e técnicas de pesquisas, elaboração análise e interpretação de dados. (3.ed.) São Paulo: Atlas, 231 p.

Morin, E., Keren, A. B. (2005) Terra pátria. (5.ed.) Porto Alegre: Sulina.

Nakano, M. (2000)Anteag: a autogestão como marca. In: Singer, P., Souza, A. R. (orgs.) A economia solidária no Brasil: a autogestão como resposta ao desemprego. São Paulo: Contexto.

Peixoto, H.(1999) Gestão local: o desenvolvimento como exercício substantivo de Participação e Solidariedade e Autonomia. Natal, Dissertação (Mestrado em Engenharia de Produção, UFRN).

Revista Sebrae (dezembro de 2007) Agronegócios - n. 7.

Rutkowski, J. (2007) Sustentabilidade de empreendimentos econômicos solidários: outro mundo, outra economia, outra engenharia. Encontro Internacional de Economia Solidária. "O discurso e a prática da economia solidária”, 5. São Paulo.

Sachs, I. (jan/mar.1990) Recursos emprego e financiamento do desenvolvimento de produzir sem destruir - o caso do Brasil. Revista de Economia Política. . (2004) Desenvolvimento includente, sustentável e sustentado. Rio de Janeiro: Garamond.

Sepúlveda, S.(2005) Desenvolvimento sustentável microrregional: Métodos para planejamento local. Brasília: IICA.

Singer, P. (2002) Introdução à economia solidária. São Paulo: Editora Fundação Perseu Abramo.

Veiga, J.E. da.(2005) Desenvolvimento sustentável, o desafio do século XXI. Rio de Janeiro: Editora Garamond.

Data do recebimento do artigo: 01/04/2011

Data do aceite de publicação: 27/02/2012 